\title{
Article \\ Triazolium Salt Organocatalysis: Mechanistic Evaluation of Unusual Ortho-Substituent Effects on Deprotonation
}

\author{
Peter Quinn, Matthew S. Smith, Jiayun Zhu (D, David R. W. Hodgson * ${ }^{\mathbb{D}}$ and AnnMarie C. O’Donoghue * \\ Department of Chemistry, Durham University, South Road, Durham DH1 3LE, UK; \\ peterquinn456@hotmail.com (P.Q.); matthew.s.smith2@durham.ac.uk (M.S.S.); jiayun.zhu@durham.ac.uk (J.Z.) \\ * Correspondence: d.r.w.hodgson@durham.ac.uk (D.R.W.H.); annmarie.odonoghue@durham.ac.uk (A.C.O.)
}

Citation: Quinn, P.; Smith, M.S.; Zhu, J.; Hodgson, D.R.W.; O’Donoghue, A.C. Triazolium Salt Organocatalysis: Mechanistic Evaluation of Unusual Ortho-Substituent Effects on Deprotonation. Catalysts 2021, 11, 1055. https://doi.org/10.3390/ catal11091055

Academic Editor: Cristina Trujillo

Received: 7 August 2021

Accepted: 25 August 2021

Published: 30 August 2021

Publisher's Note: MDPI stays neutral with regard to jurisdictional claims in published maps and institutional affiliations.

Copyright: (c) 2021 by the authors. Licensee MDPI, Basel, Switzerland. This article is an open access article distributed under the terms and conditions of the Creative Commons Attribution (CC BY) license (https:// creativecommons.org/licenses/by/ $4.0 /)$.

\begin{abstract}
Organocatalysis by N-heterocyclic carbenes is normally initiated by the deprotonation of precursor azolium ions to form active nucleophilic species. Substituent effects on deprotonation have an impact on catalytic efficiency and provide insight into general catalytic mechanisms by commonly used azolium systems. Using an NMR kinetic method for the analysis of C(3)-H/D exchange, we determined $\log k_{\mathrm{ex}}-\mathrm{p} D$ profiles for three ortho-substituted $N$-aryl triazolium salts, which enables a detailed analysis of ortho-substituent effects on deprotonation. This includes N-5-methoxypyrid-2-yl triazolium salt 7 and di-ortho-methoxy and di-ortho-isopropoxyphenyl triazolium salts $\mathbf{8}$ and $\mathbf{9}$, and we acquired additional kinetic data to supplement our previously published analysis of $N$-pyrid-2-yl triazolium salt 6 . For 2-pyridyl triazoliums 6 and 7, novel acid catalysis of C(3)-H/D exchange is observed under acidic conditions. These kinetic data were supplemented by DFT analyses of the conformational preferences of $\mathbf{6}$ upon $N$-protonation. A C(3) deprotonation mechanism involving intramolecular general base deprotonation by the pyridyl nitrogen of the $\mathrm{N}(1)$-deuterated dicationic triazolium salt is most consistent with the data. We also report $k_{\mathrm{DO}}$ values (protofugalities) for deuteroxide-catalyzed exchange for 6-9. The protofugalities for $\mathbf{8}$ and $\mathbf{9}$ are the lowest values to date in the $\mathrm{N}$-aryl triazolium series.
\end{abstract}

Keywords: triazolium organocatalysis; H/D exchange; proton transfer; ortho-substituent effects

\section{Introduction}

The organocatalytic properties of $\mathrm{N}$-heterocyclic carbenes (NHCs) are well documented for a broad range of synthetic transformations, including benzoin- and acylointype reactions [1-8], transesterifications [9-19], and annulations [20-28], among many others [29-32]. For the majority of these synthetic procedures, NHCs are typically generated in situ by the deprotonation of a conjugate acid heterocyclic azolium salt. In particular, triazolium salts $\mathbf{1}$ are widely employed as precatalysts: $C(3)$ deprotonation of $\mathbf{1}$ generates the NHC, triazolylidene $\mathbf{2}$, which also has an ylidic/carbanion resonance form $\mathbf{2}^{\prime}$ (Figure 1) [33]. First described in 1995 by Enders and Teles [34-36], the triazolyl scaffold has been proven to be broadly efficient in a range of NHC-catalyzed transformations [33,37-43]. In particular, the bicyclic pyrrolidine-based triazolyl scaffold 3 reported by Knight and Leeper [44] and related triazolium systems with morpholine- and aminoindane-based structures deliver increased yields and selectivities [45-49]. In addition to the fused ring, the choice of an appropriate $N$-aryl triazolium substituent is also key to reaction efficiency and product selectivity for a given transformation [50-58]. For example, the $N$-pentafluorophenyl catalyst 4 designed by Connon and Zeitler still holds the record, to our knowledge, of being the most efficient and stereoselective catalyst for the asymmetric benzoin reaction [47].

As the initial proton transfer step for the formation of triazolylidene 2 is common to a broad range of transformations, we reported both rate constants for deprotonation (kinetic acidities or protofugalities [59]) and carbon acid $\mathrm{p} K_{\mathrm{a}}$ values for a large series of triazolium salts in aqueous solution, which included $36 \mathrm{~N}$-aryl examples [60-64]. In addition, there is 
an increasingly large body of literature data pertaining to the $\mathrm{p} K_{\mathrm{a}}$ values of the conjugate acids of NHCs in a range of solvents [65-75]. These datasets enable a detailed evaluation of the $N$-aryl substituent effect, which provides useful insight into the catalytic options for these commonly used NHC scaffolds.

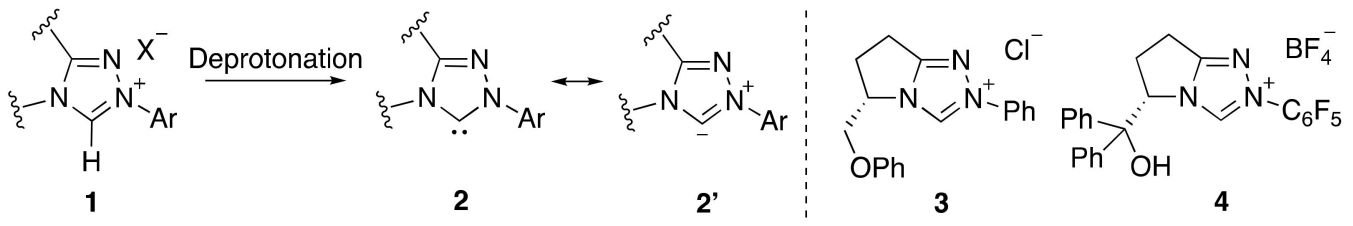

Figure 1. Triazolium salt precatalysts: $C(3)$ deprotonation to generate NHC (N-heterocyclic carbene) and common scaffolds employed in organocatalysis.

As part of these studies, we reported unusual ortho-substituent effects on the proton transfer reactions of $\mathrm{N}$-aryl triazolium salts $[50,51,63]$. For triazolium salts without ortho-substituents, $\mathrm{H} / \mathrm{D}$ exchange of $\mathrm{C}(3)-\mathrm{H}$ in $\mathrm{D}_{2} \mathrm{O}$ solution shows a simple first-order kinetic dependence on the concentration of deuteroxide, evident from a slope of +1 on a plot of $\log k_{\text {ex }}$ versus $\mathrm{p} D$ and consistent with a base-catalyzed mechanism for H/D exchange (Figure 2a). By contrast, for ortho-halo-substituted $N$-aryl triazolium salts (e.g., $N$-pentafluorophenyl triazolium 5 (Figure 2b)), significant changes in slope from $\log k_{\mathrm{ex}}-\mathrm{p} D$ proportionality were observed at low $\mathrm{pDs}$ consistent with $\mathrm{H} / \mathrm{D}$ exchange via alternative mechanism(s). We previously proposed mechanistic options to explain the altered kinetic behaviors of ortho-halo-substituted $N$-aryl triazolium salts [61]. Although there are several potential options consistent with the data, the most likely mechanistic explanation is a pathway via $\mathrm{N}(1)$-deuteration at lower $\mathrm{p} D$ values, which facilitates $\mathrm{H} / \mathrm{D}$ exchange of the resulting N(1)-deuterated dicationic triazolium salt (Figure 2b). To account for the dominance of this altered behavior for ortho-halo-substituted triazolium salts 5 , an increase in the extent of $\mathrm{N}(1)$ deuteration, and hence a more basic $\mathrm{N}(1)$, is required.

(a)

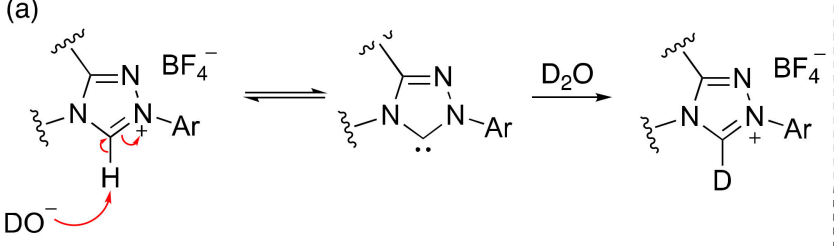

(b)<smiles></smiles><smiles>[O-][N+]1=C2CCCN2C(=Nc2c(F)c(F)c(F)c(F)c2F)C1</smiles>

(c)

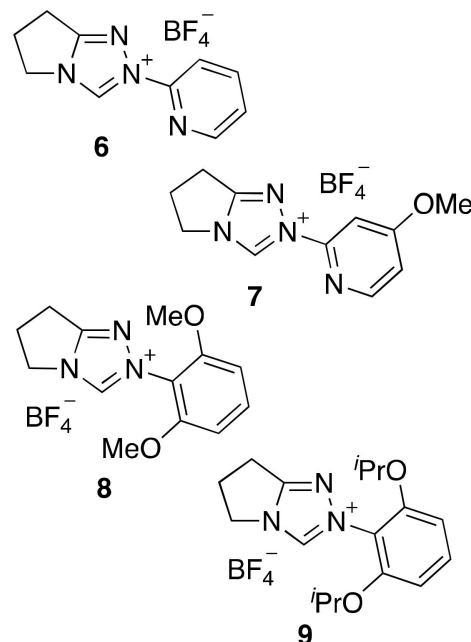

Figure 2. Mechanistic studies of the $C(3) \mathrm{H}$ / D exchange reactions of triazolium salts in $\mathrm{D}_{2} \mathrm{O}$ solution: (a) mechanism for $\mathrm{DO}^{-}$-catalyzed exchange consistent with a first-order kinetic dependence on deuteroxide ion, (b) potential mechanism for H/D exchange at low $\mathrm{pDs}$ accounting for altered dependence of $\log k_{\mathrm{ex}}$ on $\mathrm{p} D$ for ortho-halo $N$-aryl triazolium salts (e.g., 5), (c) $N$-pyrid-2-yl and $N$-5-methoxypyrid-2-yl triazolium salts 6 and 7 and di-ortho-methoxy and di-ortho-isopropoxyphenyl triazolium salts 8 and 9.

Triazolium salt 6 with an ortho-nitrogen atom in the $N$-pyrid-2-yl aryl substituent (Figure 2c) uniquely demonstrated formal acid catalysis of $\mathrm{H} / \mathrm{D}$ exchange at lower $\mathrm{p} D$ 
values, evident from a slope of close to -1 on a plot of $\log k_{\mathrm{ex}}$ versus $\mathrm{p} D$, which was not observed for any other triazolium ion [63]. This provided evidence for the potential role of the N-pyrid-2-yl substituent as an intramolecular catalyst, although the precise form of catalysis has not been unequivocally established. Related studies involving mechanistic analysis of triazolium-catalyzed benzoin and Stetter-type reactions have highlighted that these ortho-substituent effects have also been observed in other steps in addition to the initial NHC-generating step. Rate and equilibrium constants for the formation of the first tetrahedral intermediate from the addition of NHC to aldehyde are substantially altered with ortho-heteroatom aryl substituents in both the $\mathrm{N}$-aryl of catalyst and aldehyde, in comparison with analogues bearing para- or ortho-alkyl substitution [51].

To further probe the mechanistic origin of $\mathrm{N}$-aryl ortho-substituent effects, and in particular to investigate the dominant form of catalysis for the $\mathrm{N}$-pyrid-2-yl triazolium salt 6, we herein report a detailed kinetic evaluation by ${ }^{1} \mathrm{H}$ NMR of the H/D exchange reactions of three additional triazolium salts, 7, 8, and 9 . By tuning the basicity of the pyridyl nitrogen through the introduction of an electron-donating methoxy substituent in 7 , it was postulated that any resulting changes in the $\log k_{\mathrm{ex}}-\mathrm{p} D$ profile would provide mechanistic insight into the role of the pyridyl substituent. In addition, the study of orthoalkoxy-substituted triazolium salts in $\mathbf{8}$ and $\mathbf{9}$ would reveal whether the alternative proton transfer pathways observed for the ortho-halo analogues were unique or could extend to other ortho-heteroatoms. Our previous results suggest that ortho-alkyl substituents do not show any unusual behavior [61]. For $N$-mesityl triazolium salts with ortho-methyl substituents, there was no significant deviation from a slope of +1 except for slight upward deviation of one datapoint at the lowest $\mathrm{p} D$ value.

Our quantitative kinetic and structure-activity analyses provide useful insight into the mechanistic intricacies of triazolium catalysis. Although triazolium salts are a well-studied NHC organocatalyst class, there remain challenges in their usage in relation to both the stereo- and chemoselectivity of product formation, particularly in more polar media such as water. As one example of the benefits of heteroatom substitution in the NHC scaffold, recent intriguing results from Milo and coworkers demonstrated the importance of secondary sphere interactions in improving enantioselectivity in NHC organocatalysis of the benzoin reaction (as an archetypal NHC-catalyzed process) [76,77]. By invoking dynamic covalent interactions between boronic acid secondary sphere modifiers and the hydroxy substituent on the scaffold of chiral $N$-pentafluorophenyl triazolium salt 4, enantioselectivities were significantly increased. Thus, we hypothesize that alternative heteroatom substitution in the NHC scaffold, such as the ortho-pyridyl nitrogen of $\mathbf{6}$ and 7, could facilitate the greater adoption of this approach towards improving enantioselectivity in a broader range of transformations and different solvents.

\section{Results and Discussion}

2.1. Kinetic Analysis of the C(3)-H/D Exchange Reactions of N-Pyridyl Triazolium Salts $\mathbf{6}$ and $\mathbf{7}$

$\mathrm{N}$-pyrid-2-yl triazolium tetrafluoroborate $\mathbf{6}$ was prepared as described previously [63] A synthesis of N-5-methoxy-pyrid-2-yl triazolium salt 7 was not reported previously, and we employed the route shown in Scheme 1. A Buchwald-Hartwig amination [78-80] using benzophenone hydrazone $\mathbf{1 0}$ and 2-chloro-4-methoxypyridine $\mathbf{1 1}$ was employed, which yielded $N$-aryl hydrazone 12 . Subsequent acid-catalyzed hydrolysis, initially to the hydrazinium chloride, followed by neutralization using sodium hydroxide, yielded the aryl hydrazine 13. Onward conversion to triazolium tetrafluoroborate 7 employed the widely used method reported by Rovis [81]: reaction of aryl hydrazine 13 with 5-methoxy3,4-dihydro-2H-pyrrol-1-ium tetrafluoroborate yielded amidrazone 14 with subsequent cyclization being elicited by triethylorthoformate to afford 7 . The $\mathrm{X}$-ray crystal structures (CCDC 2100846-2100847) obtained in the course of this work of both triazolium tetrafluoroborate salts 6 and 7 are shown in Figure 3. 

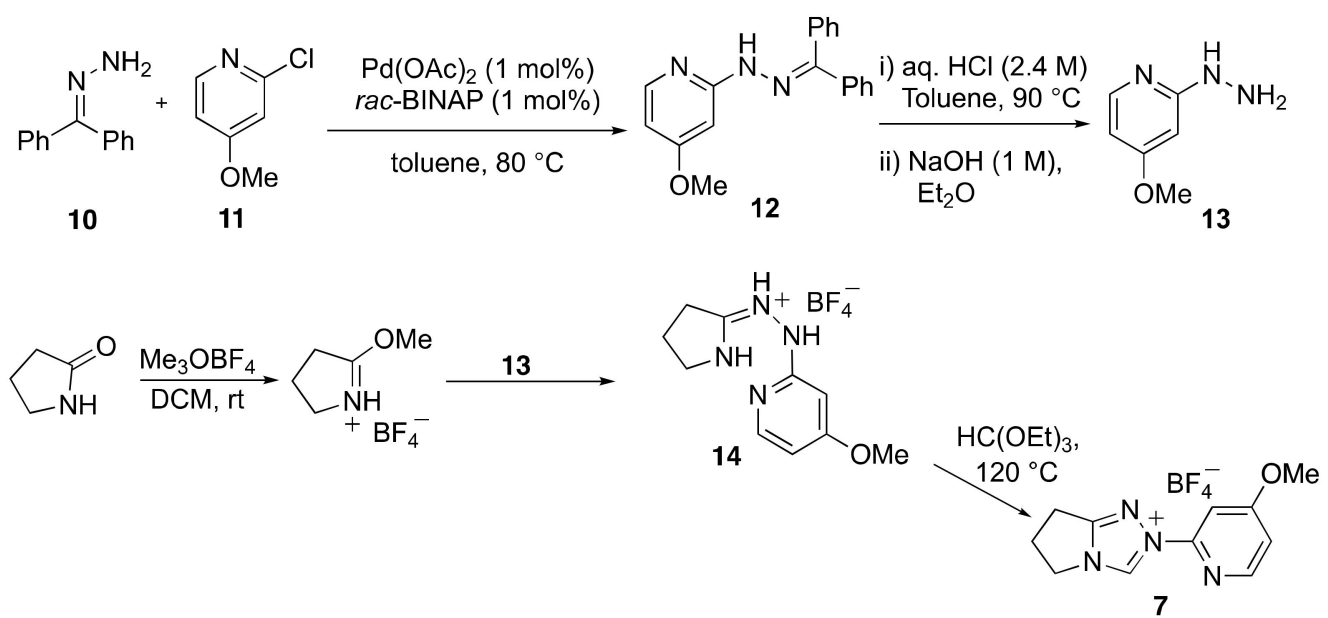

Scheme 1. Synthesis of N-5-methoxy-pyrid-2-yl triazolium tetrafluoroborate 7.
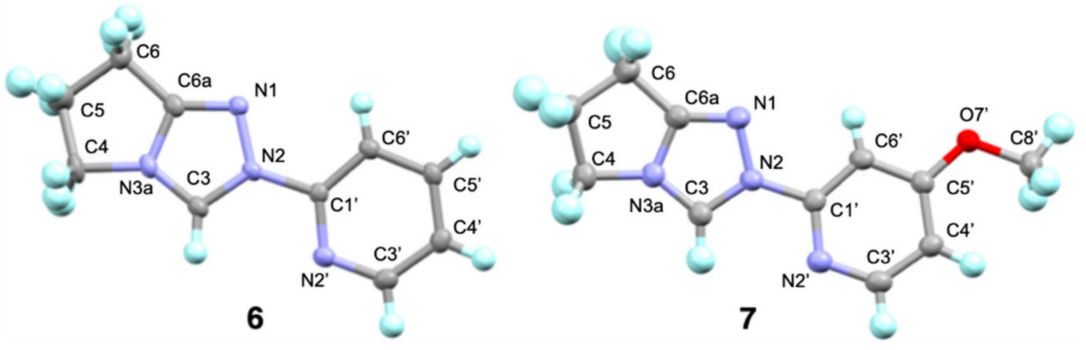

Figure 3. ORTEP diagrams from X-ray crystal structures of N-pyrid-2-yl and N-5-methoxy-pyrid-2-yl triazolium tetrafluoroborate salts 6 and 7 (counterions not shown).

The N-5-methoxy-pyrid-2-yl triazolium salt 7 had not been studied previously; thus a $\log k_{\mathrm{ex}}-\mathrm{p} D$ profile was determined in the $\mathrm{p} D$ range $0-4$. Exchange reactions were performed in both $\mathrm{DCl}$ and formate buffer solutions at $25^{\circ} \mathrm{C}$ and ionic strength, $I=1.0(\mathrm{KCl})$. For the N-pyrid-2-yl analogue 6, we previously reported a $\log k_{\mathrm{ex}}-\mathrm{p} D$ profile [63]; however, additional data were acquired in the present study in the $\mathrm{pD} 3-4$ region to assist with mechanistic evaluation and more robust kinetic fitting. For both 6 and 7, reactions were too fast above $\mathrm{pD} 4$ for NMR analysis. The kinetic and NMR methods used for the analysis of the $C(3)-\mathrm{H} / \mathrm{D}$ exchange reactions described herein were identical to those reported by us previously $[60,61,63,64]$. Over time, the disappearance of the singlet at $\sim 10.3 \mathrm{ppm}$ due to the $\mathrm{C}(3)-\mathrm{H}$ is observed; however, there is no change in the integrals of all other signals, nor in the appearance of new signals. Figures S1-S2 in Supplementary Materials include representative ${ }^{1} \mathrm{H}$ NMR spectral overlays at three time points during C(3)-H/D exchange for $\mathbf{6}$ and 7 , respectively. The observed first-order rate constants for $C(3)-\mathrm{H} / \mathrm{D}$ exchange at a given $\mathrm{p} D, k_{\mathrm{ex}}\left(\mathrm{s}^{-1}\right)$, were obtained as slopes of semilogarithmic plots of the fraction of the remaining unexchanged substrate, $f(\mathrm{~s})$, against time according to Equation (1) (Figures S3-S5). Reaction progress was defined by values of $f(\mathrm{~s})$ calculated using Equation (2), where $A_{C(3)-\mathrm{H}}$ and $A_{\text {std }}$ are the integrated areas of the singlet at $\sim 10.3 \mathrm{ppm}$ due to the $C(3)-\mathrm{H}$ of the substrate and the broad triplet at $3.3 \mathrm{ppm}$ owing to the methyl hydrogens of the internal standard, tetramethylammonium deuteriosulfate. The resulting $k_{\mathrm{ex}}\left(\mathrm{s}^{-1}\right)$ values obtained at each $\mathrm{p} D$ are collected in Tables S1 and S2 for 6 and 7.

$$
\begin{gathered}
\ln f(\mathrm{~s})=-k_{\mathrm{ex}} t \\
f(\mathrm{~s})=\left(A_{C(3)-\mathrm{H}} / A_{\mathrm{std}}\right)_{\mathrm{t}} /\left(A_{C(3)-\mathrm{H}} / A_{\mathrm{std}}\right)_{0}
\end{gathered}
$$


Figure $4 \mathrm{a}$ shows the corresponding $\log k_{\mathrm{ex}}-\mathrm{p} D$ profiles for 6 and 7. Pleasingly, the same overall kinetic behavior is observed for the H/D exchange reactions of the 5-methoxy2-pyridyl triazolium salt 7, as previously observed for $\mathbf{6}$. Both profiles show distinct regions of close to -1 and +1 slopes consistent with first-order kinetic dependencies on $\mathrm{D}_{3} \mathrm{O}^{+}$and $\mathrm{DO}^{-}$, respectively. The formal dependence on $\mathrm{D}_{3} \mathrm{O}^{+}$is unique to these 2-pyridyl salts, whereas all triazolium salts to date have shown a kinetic dependence on $\mathrm{DO}^{-}$. Significantly, $\log k_{\text {ex }}$ values in the lower $\mathrm{p} D$ region are substantially higher for $\mathbf{7}$ than for $\mathbf{6}$, showing that the 5-methoxy substituent on the pyridyl ring has increased reactivity to $\mathrm{H} / \mathrm{D}$ exchange. For comparison, the plots in Figure $4 \mathrm{~b}$ include $\log k_{\mathrm{ex}}-\mathrm{p} D$ data for $N$-pentafluorophenyl triazolium tetrafluoroborate 5 and $\mathrm{N}$-phenyl triazolium tetrafluoroborate $\mathbf{1 5}$ taken from our previously published studies [61].

(a)

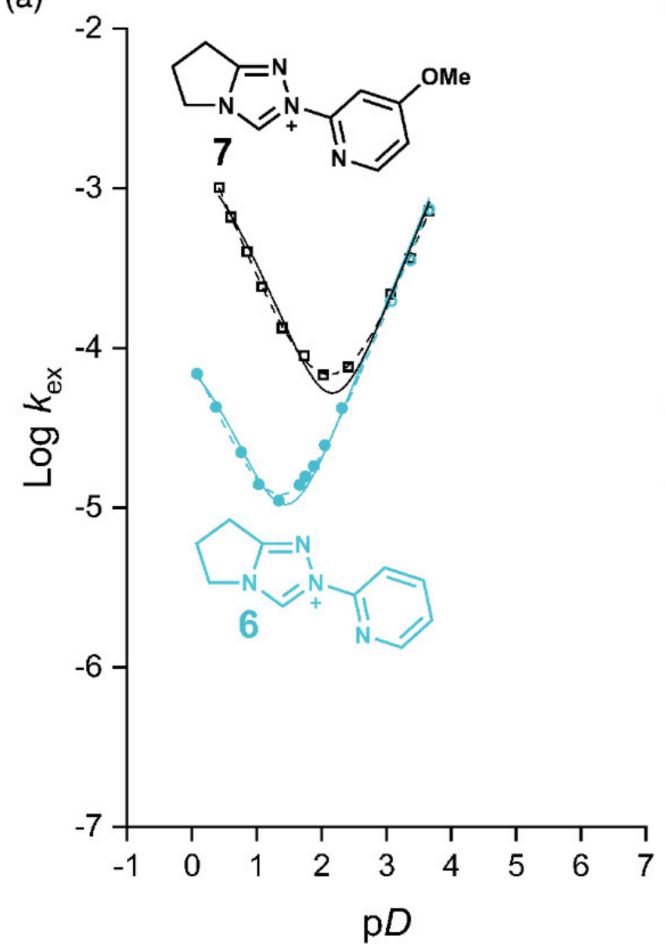

(b)

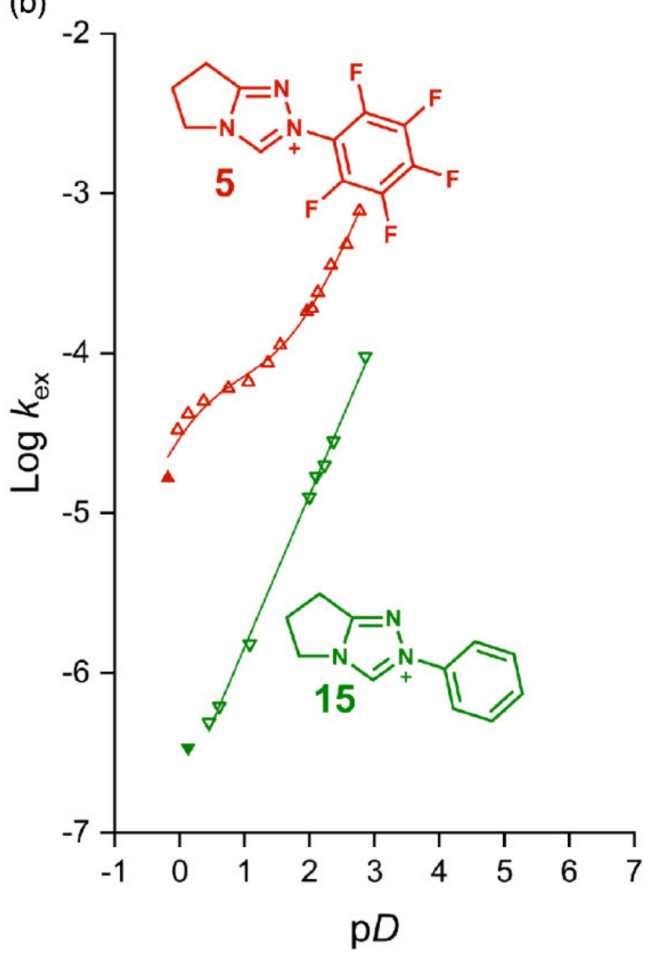

Figure 4. (a) $\mathrm{p} D$-rate profiles for the $C(3)-\mathrm{H} / \mathrm{D}$ exchange reactions of $N$-pyrid-2-yl $6(\bigcirc$; $\bullet$, previously published data) and N-5-methoxy-pyrid-2-yl triazolium $7(\square)$ tetrafluoroborate salts in DCl or buffer solutions in $\mathrm{D}_{2} \mathrm{O}$. The solid and dashed lines show the fits of reaction data to Equations (3) and (4), respectively. (b) Plotted for comparison are $\log k_{\mathrm{ex}}-\mathrm{p} D$ data taken from R. S. Massey et al. [61] for $N$-pentafluorophenyl triazolium tetrafluoroborate $\mathbf{5}(\triangle ; \boldsymbol{\Delta}$, data not included in fitting) and $N$-phenyl triazolium tetrafluoroborate $\mathbf{1 5}(\nabla ; \boldsymbol{\nabla}$, data not included in fitting).

The solid lines in Figure 4a show the fits of the reaction data to Equation (3) [82], which was used in our previous analysis of reaction data for 6 . In this equation, the H/D exchange reaction of the substrate in the region of close to +1 slope is described by the rate constant, $k_{\mathrm{DO}}\left(\mathrm{M}^{-1} \mathrm{~s}^{-1}\right)$, the second-order rate constant for deuteroxide-catalyzed exchange of the triazolium salts. $K_{\mathrm{w}}=10^{-14.87}$ is the ion product of $\mathrm{D}_{2} \mathrm{O}$ at $25^{\circ} \mathrm{C}$, and $\gamma_{\mathrm{DO}}=0.73$ is the activity coefficient for deuteroxide ion under our experimental conditions. The H/D exchange reaction of the substrate in the region of close to -1 slope is described by the rate constant, $k_{\mathrm{H}}\left(\mathrm{s}^{-1}\right)$ [83].

$$
\log \left(k_{\mathrm{ex}}\right)=\log \left[\frac{k_{\mathrm{H}}\left(10^{-\mathrm{p} D}\right)+K_{\mathrm{a}}^{\mathrm{N}}\left(\frac{k_{\mathrm{DO}} K_{\mathrm{W}}}{\gamma_{\mathrm{DO}}}\right) 10^{\mathrm{p} D}}{K_{\mathrm{a}}{ }^{\mathrm{N}}+10^{-\mathrm{p} D}}\right]
$$


This equation allows for speciation between the monocationic triazolium ion ( 6 or 7) and a conjugate acid dication obtained by protonation at either the triazolyl N(1) or 2pyridyl $\mathrm{N}$ as $\mathrm{pD}$ is decreased, and defined by the acid dissociation constant, $K_{\mathrm{a}} \mathrm{N}$. Excellent fits of the reaction data are observed for both 6 and 7 at the two ends of the plots, and values obtained from this fitting for both $k_{\mathrm{DO}}$ and $k_{\mathrm{H}}$ are shown in Table 1 . There is more uncertainty associated with a potential value for $K_{\mathrm{a}} \mathrm{N}$. The plots do not level to a plateau at the lowest $\mathrm{p} D$ values in a manner consistent with full protonation. Linear plots of only log $k_{\text {ex }}$ values at the lowest $\mathrm{pDs}$ (Figure S6) yield slopes of -0.73 and -0.93 for 6 and 7 , which are slightly below unity, suggesting the beginning of curvature. However, as this curvature is not substantial, there will be large errors associated with the determination of $K_{\mathrm{a}}{ }^{\mathrm{N}}$. The fit to Equation (3) yields $K_{\mathrm{a}}{ }^{\mathrm{N}}=0.86( \pm 0.39)$ and $0.57( \pm 0.29)$ for 6 and 7, respectively. By fixing $K_{\mathrm{a}}^{\mathrm{N}}$ at defined values of $1,10,100$, and 1000 (i.e., $\mathrm{p} K_{\mathrm{a}}{ }^{\mathrm{N}}=0,-1,-2,-3$ ), both visible inspection and the magnitude of $\mathrm{R}^{2}$ indicate that the best fit is obtained for $K_{\mathrm{a}}{ }^{\mathrm{N}}=1$ in both cases (See Figure S7).

Table 1. Kinetic parameters from fitting of H/D exchange kinetic data for 6-9 and comparison with previous data for 15-17.

\begin{tabular}{|c|c|c|c|c|c|}
\hline Triazolium Salt & $k_{\mathrm{DO}}\left(\mathrm{M}^{-1} \mathrm{~s}^{-1}\right)$ & $k_{\mathrm{H}}\left(\mathrm{s}^{-1}\right)$ & $k_{\text {in }}\left(\mathrm{s}^{-1}\right)$ & Fit & $\mathrm{p} K_{\mathrm{a}}[C(3)-\mathrm{H}]^{3}$ \\
\hline 6 & $\begin{array}{l}1.01( \pm 0.05) \times 10^{8} \\
8.79( \pm 0.30) \times 10^{7}\end{array}$ & $\begin{array}{l}1.35( \pm 0.44) \times 10^{-4} \\
4.36( \pm 3.52) \times 10^{-4}\end{array}$ & $1.97 \times 10^{-51}$ & $\begin{array}{l}\text { Equation }(3) \\
\left(\mathrm{R}^{2}=0.991\right) \\
\text { Equation }(4) \\
\left(\mathrm{R}^{2}=0.998\right)\end{array}$ & 17.4 \\
\hline 7 & $\begin{array}{l}9.57( \pm 0.84) \times 10^{7} \\
8.02( \pm 0.22) \times 10^{7}\end{array}$ & $\begin{array}{l}2.22( \pm 0.93) \times 10^{-3} \\
2.30( \pm 35.9) \times 10^{-1}\end{array}$ & $2.59 \times 10^{-31}$ & $\begin{array}{l}\text { Equation }(3) \\
\left(\mathrm{R}^{2}=0.976\right) \\
\text { Equation }(4) \\
\left(\mathrm{R}^{2}=0.999\right)\end{array}$ & 17.5 \\
\hline $\begin{array}{c}\mathrm{BF}_{4}^{-} \\
\mathrm{M} \\
8\end{array}$ & $3.87( \pm 0.07) \times 10^{7}$ & - & - & $\begin{array}{c}\text { Equation (5) }{ }^{2} \\
\left(R^{2}=0.999\right)\end{array}$ & 17.8 \\
\hline $9^{i P r}$ & $2.87( \pm 0.13) \times 10^{7}$ & - & - & $\begin{array}{c}\text { Equation (5) } \\
\left(R^{2}=0.999\right)\end{array}$ & 17.9 \\
\hline & $6.82 \times 10^{74}$ & - & - & Equation (5) & $17.5^{4}$ \\
\hline & $4.20 \times 10^{74}$ & - & - & Equation (5) & $17.8^{4}$ \\
\hline$F_{4}^{-}$ & $5.29 \times 10^{74}$ & - & - & Equation (5) & $17.7^{4}$ \\
\hline
\end{tabular}

${ }^{1}$ The error in $k_{\text {in }}$ is high owing, in part, to the limited number of datapoints in this region. ${ }^{2}$ See Section $2.2 .{ }^{3}$ Calculated as described in Section 2.3. ${ }^{4}$ Determined by us previously (see R. S. Massey et al. [61]).

In the middle region of the $\mathrm{p} D$-rate profile for the lowest $\log k_{\text {ex }}$ values, where the transition occurs between negative and positive slopes, there are several datapoints that deviate above the curve described by Equation (3). This is more significant for the 5methoxy-2-pyridyl triazolium salt 7 and could potentially be explained by an additional $\mathrm{p} D$-independent process. To allow for this third option, we included a $\mathrm{p} D$-independent term, defined by the rate constant $k_{\text {in }}\left(\mathrm{s}^{-1}\right)$ in Equation (4) (Figure 4a, dashed line) [82]. The overall fit for $\mathbf{6}$ is similar, but there is a significant improvement in the overall fit for $7\left(R^{2}=0.999\right.$ versus 0.976$)$; however, we must caution that the inclusion of an additional 
variable will always lead to an improvement in overall kinetic fitting whether its inclusion is mechanistically justified or not. In addition, there is a large increase in the error for $k_{\mathrm{H}}$ when using Equation (4).

$$
\log \left(k_{\mathrm{ex}}\right)=\log \left[\frac{k_{\mathrm{H}}\left(10^{-\mathrm{p} D}\right)+k_{\mathrm{in}}+K_{\mathrm{a}}^{\mathrm{N}}\left(\frac{k_{\mathrm{DO}} K_{\mathrm{W}}}{\gamma_{\mathrm{DO}}}\right) 10^{\mathrm{p} D}}{K_{\mathrm{a}}{ }^{\mathrm{N}}+10^{-\mathrm{p} D}}\right]
$$

The following sections will evaluate the potential mechanistic options that can be aligned with the different regions of the $\log k_{\mathrm{ex}}-\mathrm{p} D$ profiles.

2.1.1. Mechanistic Options for the Region of +1 Slope in $\log k_{\mathrm{ex}}-\mathrm{p} D$ Profiles at Higher $\mathrm{pD}$ Values (First-Order Dependence on $\mathrm{DO}^{-}$)

The first-order dependence on deuteroxide ion in this region of the profile is consistent with a single mechanism for deuteroxide-catalyzed H/D exchange, as shown in Figure 5: $C$ (3) deprotonation of the triazolium salts by deuteroxide results in the formation of a complex between the triazolyl NHCs and a molecule of HOD. Subsequent reorganization of NHC.HOD to NHC.DOL ( $\mathrm{L}=\mathrm{H}$ or D) to allow for the delivery of deuterium, followed by deuteration, leads to a $C(3)$-deuterated product. Owing to the large excess of bulk solvent over the substrate, the deuteration step is effectively irreversible; thus $k_{\text {ex }}$ reflects a ratelimiting formation of solvent-equilibrated NHC from the triazolium salt and deuteroxide ion at a given $\mathrm{p} D$. By definition, the second-order rate constant, $k_{\mathrm{DO}}\left(\mathrm{M}^{-1} \mathrm{~s}^{-1}\right)$, is the observed $k_{\text {ex }}$ value in $1 \mathrm{M}$-solution ( $\mathrm{p} D \sim 14$ ). Experimentally, $C(3)-\mathrm{H} / \mathrm{D}$ exchange for all triazolium ions is orders of magnitude too fast to monitor directly by NMR in $1 \mathrm{M} \mathrm{DO}^{-}$ (half-lives $\sim$ nanoseconds); thus $k_{\mathrm{DO}}$ values are obtained by the assessment of a range of $k_{\mathrm{ex}}$ values at lower $\mathrm{pDs}$, as described above. The reactivities to deprotonation by a common base, $k_{\mathrm{DO}}$, allow for the evaluation of the protofugalities of the $C(3)$ hydrogens in the series of triazolium ions.

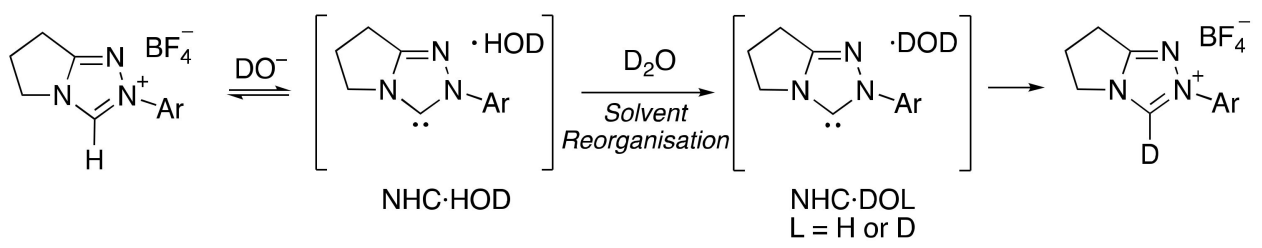

Figure 5. Mechanism for $\mathrm{H} / \mathrm{D}$ exchange consistent with first-order dependence on $\mathrm{DO}^{-}$.

In our previous studies, $k_{\mathrm{DO}}$ values for $N$-aryl triazolium ions spanned a range of $\sim 30$ fold across the large series [60-64]. Maximal $k_{\text {DO }}$ values $\left(\sim 8 \times 10^{8} \mathrm{M}^{-1} \mathrm{~s}^{-1}\right)$ were observed for $\mathrm{N}$-pentafluorophenyl-substituted triazolium salts, whereas the lowest value to date of $4.2 \times 10^{7} \mathrm{M}^{-1} \mathrm{~s}^{-1}$ was observed for an N-4-methoxyphenyltriazolium salt 16 . Typically, values for $k_{\mathrm{DO}}$ were observed to increase for electron-withdrawing $N$-aryl substituents. In the present study, values of $k_{\mathrm{DO}}=8.79 \times 10^{7} \mathrm{M}^{-1} \mathrm{~s}^{-1}$ and $8.02 \times 10^{7} \mathrm{M}^{-1} \mathrm{~s}^{-1}$ were obtained for 6 and 7 (Table 1), respectively, which fall midway in the range of previously observed values. The extra data obtained herein for 6 in $\mathrm{pD}$ regions 3-4 permit a more reliable determination of $k_{\mathrm{DO}}$. These $k_{\mathrm{DO}}$ values for 6 and 7 are higher than for $N$-phenyl triazolium salt 15, indicating an overall electron-withdrawing effect of both pyridyl substituents. Electron-withdrawing $N$-aryl substituents will destabilize the cationic triazolium carbon acid relative to the formally neutral NHC conjugate base, thus favoring the deprotonation process. The $k_{\mathrm{DO}}$ values obtained for $\mathbf{6}$ and $\mathbf{7}$ are closely similar, suggesting that the electronwithdrawing 2-pyridyl nitrogen dominates the $\mathrm{N}$-aryl substituent effect for deuteroxidecatalyzed exchange. The value for 7 is $\sim 10 \%$ lower than for $\mathbf{6}$, as would be expected with the additional presence of a donating 5-methoxy substituent. There is no evidence of intramolecular catalysis involving the pyridyl substituent in this region as the $k_{\mathrm{DO}}$ values fall within the normal range observed to date and can be explained by the normal electronwithdrawing substituent effect of the 2-pyridyl group. A substantially higher $k_{\mathrm{DO}}$ value 
would have been expected if intramolecular catalysis were operational. Presumably, the intrinsic reactivity to intermolecular deprotonation by $\mathrm{DO}^{-}$is so high in this $\mathrm{pD}$ region that there is no competition from an intramolecular reaction.

\subsubsection{Mechanistic Options for the Region of -1 Slope in $\log k_{e x}-p D$ Profile (First-Order} Dependence on $\mathrm{D}_{3} \mathrm{O}^{+}$)

Formal $\mathrm{D}_{3} \mathrm{O}^{+}$catalysis, as observed in this region of the profile, is unique to 6 and 7 and has not been observed to date in proton transfer studies for any other $N$-aryl triazolium salt. For all other triazolium salts, including $N$-pentafluorophenyl triazolium 5 , rate constants for $\mathrm{H} / \mathrm{D}$ exchange continue to decrease as $\mathrm{pD}$ is decreased (e.g., as shown in Figure $4 \mathrm{~b}$ for 5 and 15). To account for the increase in $k_{\mathrm{ex}}$ for $\mathbf{6}$ and $\mathbf{7}$ at lower $\mathrm{pDs}$, it is necessary to invoke a mechanism that is not possible, or would be substantially slower, for other triazolium ions. Importantly, $k_{\mathrm{ex}}$ rate constants for $\mathbf{7}$ are at least 15 -fold higher than for $\mathbf{6}$ in this region, and any mechanism should allow for this difference in reactivity.

As both $\mathbf{6}$ and $\mathbf{7}$ contain two nitrogen atoms with lone electron pairs, the most logical mechanisms for acid catalysis will involve deuteration at one of these atoms. $\mathrm{N}$-deuteration of the triazolium salt will eventually occur as the $\mathrm{p} D$ decreases, although the precise $K_{\mathrm{a}}$ is unknown. Possibilities include $\mathrm{N}(1)$-deuteration of the triazolium ring (Option a or $\mathbf{d}$, Figure 6), deuteration of the 2-pyridyl nitrogen (Option b, Figure 6), and shared deuteration between both nitrogens (Option c, Figure 6). Mechanisms involving pre-equilibrium Ndeuteration to any of these three dicationic species, followed by $C(3)$ deprotonation by solvent, as shown in Options a-d, which are kinetically equivalent, would result in formal acid catalysis. Option $\mathbf{d}$ additionally involves the participation of the 2-pyridyl nitrogen as an intramolecular general base catalyst in the activation of water.<smiles>[X]c1ccnc(-c2nc3n([n+]2[2H])CC[C@H]3COC(=O)[O-])c1</smiles><smiles></smiles>

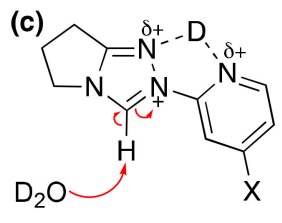

(d)

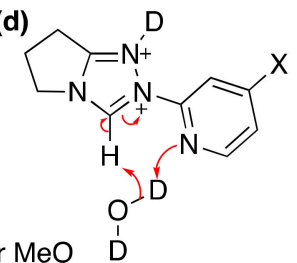

Figure 6. Mechanistic options for deprotonation consistent with a formal first-order dependence on $\mathrm{D}_{3} \mathrm{O}^{+}$: (a) $N(1)$-deuteration of triazolium with subsequent $C$ (3)-deprotonation by solvent $\mathrm{D}_{2} \mathrm{O} ;(\mathbf{b})$ $\mathrm{N}$-pyridyl deuteration of triazolium followed by $\mathrm{C}(3)$-deprotonation by solvent $\mathrm{D}_{2} \mathrm{O}$; (c) Shared intramolecular deuteration of both $N(1)$ and the 2-pyridyl nitrogen with subsequent $C$ (3)-deprotonation by solvent $\mathrm{D}_{2} \mathrm{O}$; (d) N(1)-deuteration of triazolium with subsequent $C$ (3)-deprotonation by solvent $\mathrm{D}_{2} \mathrm{O}$ and general base catalysis by 2-pyridyl substituent.

Option a can be excluded, as there is no reason why a nonparticipating remote 2pyridyl substituent should result in orders of magnitude increases in rate constants in this region compared with other $N$-aryl substituents. In the $\mathrm{DO}^{-}$region of +1 slope, the $k_{\mathrm{DO}}$ values obtained for $\mathbf{6}$ and $\mathbf{7}$ fall midway in the range of previously observed rate constants and are not unusually high. It is thus difficult to justify why a remote nonparticipating pyridyl could substantially increase a $\mathrm{D}_{2} \mathrm{O}$ reaction but not a $\mathrm{DO}^{-}$reaction.

Option $\mathbf{b}$ is potentially more chemically reasonable as the range of triazolium salts studied previously did not contain a more basic heteroatom in an ortho-position. This option, which involves electrophilic catalysis by an $N$-protonated pyridyl substituent, would be unique to the 2-pyridyl salts 6 and 7 . However, the question then arises as to how protonation on the 2-pyridyl nitrogen could result in an increase in $k_{\mathrm{ex}}$, whereas with 
$\mathrm{N}$ (1)-deuteration on the central triazolium ring, as proposed for ortho-halo salts (e.g., 5, Figures $2 \mathrm{~b}$ and $4 \mathrm{~b}$ ), rate constants continue to decrease with $\mathrm{p} D$. A significantly higher $\mathrm{p} K_{\mathrm{a}}{ }^{\mathrm{N}}$ for acid dissociation of the $\mathrm{N}$-protonated pyridyl than triazolyl nitrogen could explain this difference in trends. A higher degree of pyridyl $\mathrm{N}$-deuteration owing to a higher $\mathrm{p} K_{\mathrm{a}}{ }^{\mathrm{N}}$, and hence a higher formal cationic charge at this position, would enhance electron deficiency and facilitate the deprotonation at $C(3)$ by solvent. As discussed earlier, however, there is no evidence from the $\mathrm{p} D$ profile that $\mathrm{p} K_{\mathrm{a}}{ }^{\mathrm{N}}$ is significantly greater than zero for $\mathbf{6}$ or even the more basic 5-methoxypyridyl-substituted 7. Similar $\mathrm{p} K_{\mathrm{a}}{ }^{\mathrm{N}}$ values $\sim-0.3$ were estimated for ortho-halo-substituted salts from reaction data, albeit with relatively large errors in $K_{\mathrm{a}}{ }^{\mathrm{N}}$. In a similar manner, Option $\mathbf{c}$ with a shared intramolecular deuteration would also require an elevated $\mathrm{pK}_{\mathrm{a}}{ }^{\mathrm{N}}$ compared with other triazolium salts in order to account for the substantial increase in rate constants in the -1 region.

Option $\mathbf{d}$ is not reliant on an elevated $\mathrm{pK}_{\mathrm{a}}{ }^{\mathrm{N}}$ and utilizes the pyridyl nitrogen as an intramolecular general base catalyst (i.e., protonation on the pyridyl nitrogen is not required). In particular, our present results for 7 also add support to this mechanism as intramolecular deprotonation by a more basic 4-methoxyl pyridyl nitrogen would be expected to be close to two orders of magnitude faster than for 6 (note: $\mathrm{p} K_{\mathrm{a}}\left(\mathrm{H}_{2} \mathrm{O}\right)=5.17$ and 6.62 for pyridinium and 4-methoxypyridinium salts, respectively).

We computationally studied the conformational profiles of both the monocationic and dicationic $\mathrm{N}$-2-pyridyl triazolium ion as a function of the change in dihedral angle between the $N$-aryl substituent and central triazolium ring using the B3LYP/6-311++g $(\mathrm{d}, \mathrm{p})$ [84-86] level of theory (Supplementary Materials, Section S10). The preferred lowest energy conformation for the monocationic triazolium ion in water (Figure 7, black) has a coplanar $N$-aryl substituent with the pyridyl nitrogen pointing towards the $\mathrm{C}(3)-\mathrm{H}$, as observed in the experimental X-ray crystal structure for both 6 and 7 (Figure 3).
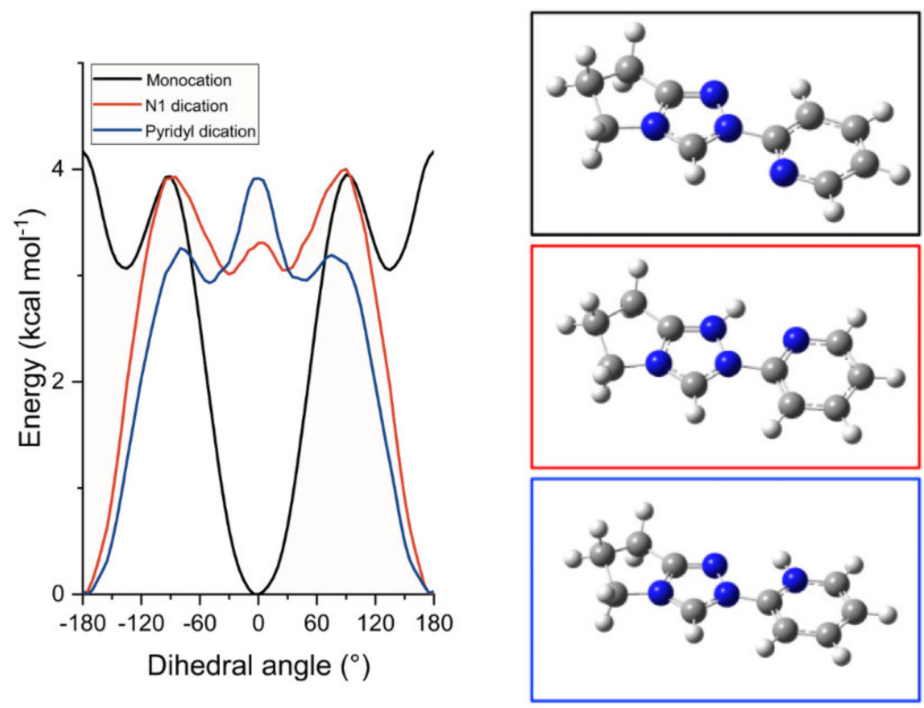

Figure 7. Conformational profiles of monocationic N-pyrid-2-yl 6 (-) and the two dicationic forms afforded from $\mathrm{N}$-protonation of the triazolyl $\mathrm{N}(1)(-)$ or the pyridyl nitrogen (—) obtained by DFT calculations using a B3LYP (6-311G++(d,p) basis set [84-86], PCM water [87]). The inset ball and stick diagrams show the structures corresponding to the lowest energy conformations of $N$-pyrid-2-yl triazolium monocation 6 (-) and the two dicationic forms (-) or (-).

Interestingly, upon $\mathrm{N}$-protonation at either $\mathrm{N}(1)$ of the triazole or the 2-pyridyl nitrogen to give a dicationic species, the preference for coplanarity remains, however, with a $180^{\circ}$ rotation of the pyridyl nitrogen such that it points towards N(1) (Figure 7, red and blue, respectively). Thus, there is a clear difference in the preferred orientation of the pyridyl nitrogen between the monocationic and dicationic triazolium species. The same conformational preferences were observed in both water and methanol as solvents (see 
Figure S15 for methanol calculations), and also using the M062X/6-311g++ (d,p) [85,86,88] level of theory for the dication calculations in water (Figure S16). In principle, this lends support to mechanistic Option c (Figure 7), which requires this preferred lowest energy conformation for the dication, but not to Option $\mathbf{d}$. However, the energy barrier for rotation around the N(2)-C $C^{\text {ipso }}(\mathrm{Ar})$ bond in all three cases (Figure 7) is only $4.0-4.1 \mathrm{kcal} \mathrm{mol}^{-1}$ at $25{ }^{\circ} \mathrm{C}$, which would permit interconversion between conformers on a subsecond timescale. Thus, all conformations are rapidly accessible on the kinetic timescale of H/D exchange.

2.1.3. Mechanistic Options for the (Potential) Region of Zero Slope in $\log \mathrm{k}_{\mathrm{ex}}-\mathrm{p} D$ Profile ( $\mathrm{pD}$-Independent Region)

In the case of 5-methoxy-2-pyridyl triazolium salt 7, there is some evidence for an additional $\mathrm{p} D$-independent process at intermediate $\mathrm{p} D$ values. The observed $k_{\mathrm{ex}}$ values at $\mathrm{p} D$ 1.7-2.5 are significantly increased above the intersection point of the regions of negative and positive slopes. In the case of 6 , some slight upward deviation of a couple of datapoints is observed, but the changes are smaller. Figure 8 shows a mechanism that could be aligned with this region of the profile: deprotonation at $C(3)$ of the monocationic triazolium salt by solvent $\mathrm{D}_{2} \mathrm{O}$ with potential intramolecular assistance from the pyridyl nitrogen. This mechanism also unifies with the mechanism that seems most consistent with the -1 region (i.e., intramolecular deprotonation at $C(3)$ by solvent (c.f. Figure 8 ) is facilitated by $\mathrm{N}(1)$-protonation, explaining the large increase in rate constants at lower $\mathrm{p} D \mathrm{~s}$ (c.f. Figure 6d)).<smiles></smiles>

Figure 8. Mechanistic option for deprotonation consistent with $\mathrm{p} D$-independent $\mathrm{H} / \mathrm{D}$ exchange.

2.2. Kinetic Analysis of the C(3)-H/D Exchange Reactions of N-di-Ortho-Alkoxy Triazolium Salts 8 and 9

For the syntheses of $N$-di-ortho-methoxy- and $N$-di-ortho-isopropoxyphenyl triazolium tetrafluoroborate salts $\mathbf{8}$ and $\mathbf{9}$, we utilized modifications of a previously reported procedure for the preparation of the analogous chloride salt of $\mathbf{8}$ (Supplementary Materials, Section S9). The C(3)-H/D exchange reactions of 8 and $\mathbf{9}$ had not been studied previously, and log $k_{\mathrm{ex}}-\mathrm{p} D$ profiles were determined in the $\mathrm{p} D$ range $0-3$. Figures $\mathrm{S} 8$ and $\mathrm{S} 9$ (Supplementary Materials, Section S7) include representative ${ }^{1} \mathrm{H}$ NMR spectral overlays at three time points during C(3)-H/D exchange for 8 and 9, respectively. As for 6 and 7, no parallel reactions were observed during the timescale for complete deuterium exchange. The observed first-order rate constants for $C(3)-\mathrm{H} / \mathrm{D}$ exchange at a given $\mathrm{p} D, k_{\mathrm{ex}}\left(\mathrm{s}^{-1}\right)$, were obtained as slopes of semilogarithmic plots of the fraction of the remaining unexchanged substrate, $f(\mathrm{~s})$, against time according to Equation (1) (Figures S10 and S12). As for all previous studies of H/D-deuterium exchange reactions of the conjugate acids of NHCs, buffer catalysis was not significant (Figures S11 and S13, Tables S5 and S6). The resulting $k_{\mathrm{ex}}\left(\mathrm{s}^{-1}\right)$ values obtained at each pD are collected in Tables S3 and S4 for 8 and $\mathbf{9 .}$

Figure 9 shows the corresponding $\log k_{\mathrm{ex}}-\mathrm{p} D$ profiles for 8 and $\mathbf{9}$. For comparison, Figure 9 also includes $\log k_{\mathrm{ex}}-\mathrm{pD}$ data for $N$-phenyl triazolium tetrafluoroborate $\mathbf{1 5}$ taken from our previously published studies [61]. In both cases, the profile is mostly described by a region of +1 slope consistent with the mechanism in Figure 6 . There is evidence of some slight upward deviation from the line of +1 slope for a few datapoints at the lowest $\mathrm{p} D$ values. Equation (5) is a simplified form of Equations (3) and (4) [82], which only allows for a first-order dependence on $\mathrm{DO}^{-}$. To determine a $k_{\mathrm{DO}}$ value, only datapoints that fit a line of unit slope were included (open symbols), and those showing slight upward deviation (filled symbols) were excluded from the kinetic fitting to Equation (5). The slight 
upward deviation is not significant enough to justify application of Equations (3) or (4) for kinetic fitting.

$$
\log \left(k_{\mathrm{ex}}\right)=\log \left[\left(\frac{k_{\mathrm{DO}} K_{\mathrm{W}}}{\gamma_{\mathrm{DO}}}\right) 10^{\mathrm{p} D}\right]
$$

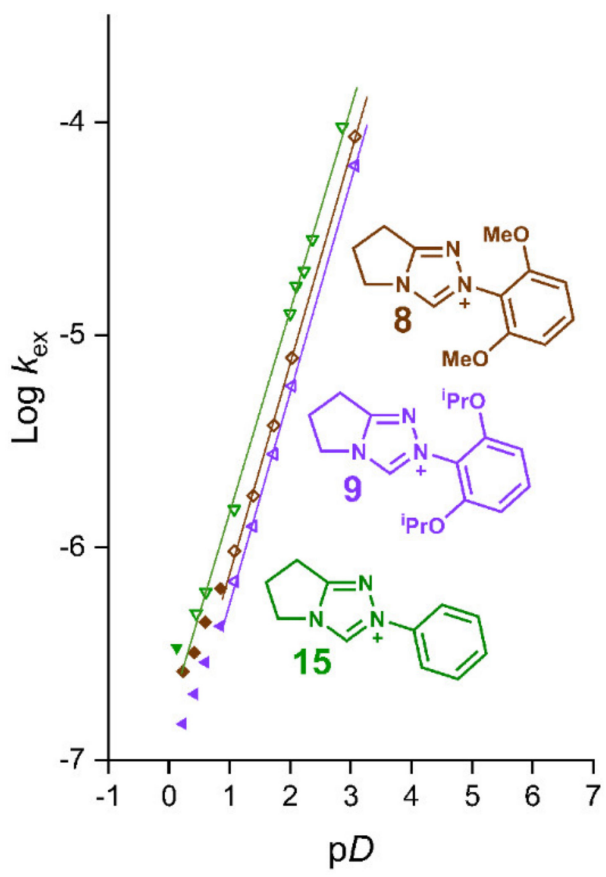

Figure 9. $\mathrm{p} D$-rate profiles for the $C(3)-\mathrm{H} / \mathrm{D}$ exchange reactions of $N$-di-ortho-methoxyphenyl 8 $(\diamond ; \triangleleft$, data not included in fitting) and $N$-di-ortho-isopropoxyphenyl $9(\triangleleft ; \triangleleft$, data not included in fitting) tetrafluoroborate salts. The solid lines show the fit of reaction data to Equation (5). Plotted for comparison are $\log k_{\mathrm{ex}}-\mathrm{p} D$ data taken from R. S. Massey et al. for $N$-phenyl triazolium tetrafluoroborate $\mathbf{1 5}(\nabla ; \boldsymbol{\nabla}$, data not included in fitting) [61].

The $k_{\mathrm{DO}}$ values for $\mathbf{8}$ and $\mathbf{9}$ (Table 1 ) are lower than for both $N$-phenyl $\mathbf{1 5}$ and $N$-mesityl 17 triazolium salts and also than the lowest $k_{\mathrm{DO}}$ to date for the $N-4$-methoxyphenyltriazolium salt 16. Clearly, di-ortho-alkoxy substitution is very different from ortho-halo substitution in not facilitating alternative pathways for $H / D$ exchange as $\mathrm{p} D$ is decreased. Furthermore, opposite effects on deuteroxide-catalyzed exchange are observed at higher $\mathrm{p} D$ s. Halo substituents result in increases in protofugality, whereas ortho-alkoxy substituents substantially decrease $k_{\mathrm{DO}}$, consistent with a net electron-donating substituent effect for the latter-reducing $C(3)$ carbon acidity.

\subsection{Estimation of Carbon Acid C(3)-H $p K_{a}$ Values}

In the determination of aqueous $\mathrm{p} K_{\mathrm{a}}$ values of weak carbon acids, the main problem is the levelling effect and the quantitative deprotonation of water. Owing to the greater basicities of most NHCs relative to hydroxide ion, quantitative deprotonation of water occurs, which prevents the determination of $\mathrm{p} K_{\mathrm{a}}$ values by direct quantification of the relative concentrations of acid and conjugate base species at equilibrium. We previously employed an alternative kinetic approach by using the rate constants for the forward and reverse directions of the proton transfer equilibrium in the calculation of $\mathrm{p} K_{\mathrm{a}}$ using Equation (6) derived for Scheme 2 [60,61,63-65]. In this equation, $k_{\mathrm{HO}}\left(\mathrm{M}^{-1} \mathrm{~s}^{-1}\right)$ is the second-order rate constant for deprotonation at $C(3)$ by hydroxide ion, which may be calculated from the corresponding $k_{\mathrm{DO}}$ value using a value of $k_{\mathrm{DO}} / k_{\mathrm{HO}}=2.4$ for the secondary solvent isotope effect on the basicity of $\mathrm{HO}^{-}$in $\mathrm{H}_{2} \mathrm{O}$ versus $\mathrm{DO}^{-}$in $\mathrm{D}_{2} \mathrm{O}$. As discussed previously [61], the absence of significant general base catalysis of deuterium exchange provides good evidence that the reverse protonation of the triazol-3-ylidene NHC 
by water is equal or close to the limiting rate constant for the physical process of solvent reorganization $\left(k_{\mathrm{HOH}} \leq k_{\text {reorg }}=10^{11} \mathrm{~s}^{-1}\right)$. The main error in $\mathrm{p} K_{\mathrm{a}}$ determination using this method is associated with the value assumed for $k_{\mathrm{HOH}}$; hence these $\mathrm{p} K_{\mathrm{a}}$ values provide upper limit estimations. Using this same approach, $\mathrm{C}(3)-\mathrm{H} \mathrm{pK} K_{\mathrm{a}}$ values were calculated for triazolium tetrafluoroborate salts $\mathbf{6 - 9}$, which range from 17.4 to 17.9 (Table 1 ). Given that values of $k_{\mathrm{DO}}$ for $6-9$ only vary by threefold $\left(2.87 \times 10^{7} \mathrm{M}^{-1} \mathrm{~s}^{-1}-8.79 \times 10^{7} \mathrm{M}^{-1} \mathrm{~s}^{-1}\right)$, and the logarithmic relationship of $k_{\mathrm{HO}}$ and $\mathrm{p} K_{\mathrm{a}}$ in Equation (6), the resulting $\mathrm{C}(3)-\mathrm{H} \mathrm{p} K_{\mathrm{a}}$ values vary by less than 1 unit. Consistent with our previous work, $N$-aryl substituent effects on $\mathrm{pK}_{\mathrm{a}}$ are relatively small. As commented previously [61], the main factor influencing the $\mathrm{p} K_{\mathrm{a}} \mathrm{s}$ of the conjugate acids of NHCs is the nature of the ring heteroatoms in the central heterocycle, while the effects of $\mathrm{N}$-aryl substituent are substantially smaller.

$$
\mathrm{p} K_{\mathrm{a}}=\mathrm{p} K_{\mathrm{w}}+\log \frac{k_{\mathrm{HOH}}}{k_{\mathrm{HO}}}
$$

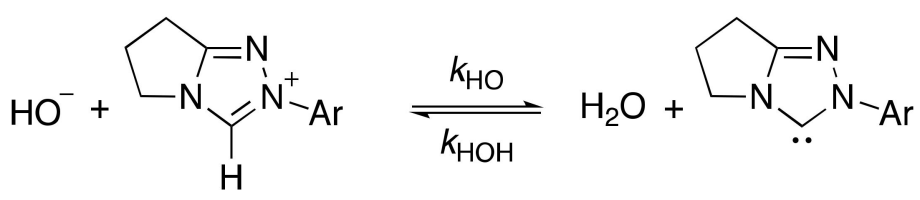

Scheme 2. Determination of $\mathrm{C}(3)-\mathrm{H} \mathrm{p} K_{\mathrm{a}}$ using a kinetic approach.

\section{Conclusions}

The $C$ (3) deprotonation of 1,2,4-triazolium salts is the first key step in all organocatalysis processes involving NHC catalysis by triazolylidenes. Structure-reactivity studies of substituent effects on this proton transfer step can provide valuable insight into the modes of catalysis possible for a given $\mathrm{N}$-aryl substituent. In order to mechanistically interrogate ortho-substituent effects on proton transfer, we reported detailed hydrogen-deuterium kinetic studies of N-5-methoxypyrid-2-yl triazolium salt 7 and di-ortho-methoxy and diortho-isopropoxyphenyl triazolium salts 8 and 9 . In each case, we evaluated the effect of a change in reaction $\mathrm{pD}$ on the rate constant for exchange, $k_{\mathrm{ex}}$, and performed a detailed kinetic evaluation of the $\log k_{\mathrm{ex}}-\mathrm{p} D$ profiles.

In common with all triazolyl NHCs studied to date, the profiles for 7-9 all included a region of +1 slope consistent with a first-order dependence on deuteroxide ion. The secondorder rate constants for deuteroxide-catalyzed exchange, $k_{\mathrm{DO}}$ (also known as the protofugality), could be measured as $8.02 \times 10^{7} \mathrm{M}^{-1} \mathrm{~s}^{-1}, 3.87 \times 10^{7} \mathrm{M}^{-1} \mathrm{~s}^{-1}$, and $2.87 \times 10^{7} \mathrm{M}^{-1} \mathrm{~s}^{-1}$ for 7-9, respectively. Relative to $N$-phenyl triazolium tetrafluoroborate 15, the 5-methoxy2-pyridyl substituent of 7 increases $k_{\mathrm{DO}}$, whereas the di-ortho-alkoxy substituents of $\mathbf{8}$ and 9 decrease $k_{\mathrm{DO}}$ consistent with electron-withdrawing and electron-donating substituent effects on protofugality, respectively. Using the values for $k_{\mathrm{DO}}$, we also estimated upper limits on $\mathrm{p} K_{\mathrm{a}}$ values for deprotonation at $C(3)$.

The $\log k_{\mathrm{ex}}-\mathrm{p} D$ profile for the $N$-5-methoxypyrid-2-yl triazolium salt 7 also demonstrated an extensive region of close to -1 slope, which had only been observed previously for N-pyrid-2-yl analogue 6, but not for any other triazolium salt. Significantly, the effect of a 5-methoxy substituent in the pyridyl ring of $\mathbf{7}$ is to increase rate constants in this region by at least 15 -fold compared with 6 . As there is no evidence for significant protonation of the pyridyl substituent above $\mathrm{p} D 0$ for either 6 or 7 , we propose that a H/D exchange mechanism involving intramolecular general base deprotonation at $C(3)$ by the pyridyl nitrogen of the N(1)-deuterated dicationic triazolium salt is more consistent with the data than one involving electrophilic catalysis with protonation on the pyridyl nitrogen.

Supplementary Materials: The following are available online at https:/ /www.mdpi.com/article/10 .3390 / catal11091055/s1: Figure S1-Representative ${ }^{1} \mathrm{H}$ NMR spectra between 11.2 and $6.8 \mathrm{ppm}$ at $500 \mathrm{MHz}$ of 6 (10 mM, pD 3.07) during exchange of $C(3)-\mathrm{H}(\mathrm{s}, 8.33 \mathrm{ppm})$ for deuterium in $\mathrm{D}_{2} \mathrm{O}$ at $25^{\circ} \mathrm{C}$ and $\mathrm{I}=1.0(\mathrm{KCl})$. [internal standard, tetramethylammonium deuteriosulphate $(\mathrm{s}, 3.17 \mathrm{ppm})$ ]. 
Figure S2-Representative ${ }^{1} \mathrm{H}$ NMR spectra between 11.2 and $6.8 \mathrm{ppm}$ at $500 \mathrm{MHz}$ of 7 (10 mM, pD 1.08) during exchange of $\mathrm{C}(3)-\mathrm{H}(\mathrm{s}, 10.39 \mathrm{ppm})$ for deuterium in $\mathrm{DCl}$ solution in $\mathrm{D}_{2} \mathrm{O}$ at $25^{\circ} \mathrm{C}$ and $\mathrm{I}=1.0(\mathrm{KCl})$. [internal standard, tetramethylammonium deuteriosulphate $(\mathrm{s}, 3.17 \mathrm{ppm})$ ]. Figure S3-Semilogarithmic plots of the fraction of unexchanged substrate against time for the C(3)-H/D exchange reaction of 6 in solutions of $\mathrm{DCl}$ in $\mathrm{D}_{2} \mathrm{O}$ at $25^{\circ} \mathrm{C}$ and $\mathrm{I}=1.0(\mathrm{KCl})$. The majority of the data for 6 (for lower $\mathrm{p} D$ values) has been previously reported. Figure S4-Semilogarithmic plots between $\mathrm{p} D=0.42$ and $\mathrm{p} D=1.73$ of the fraction of unexchanged substrate against time for the $\mathrm{C}(3)-\mathrm{H} / \mathrm{D}$ exchange reaction of 7 in solutions of $\mathrm{DCl}$ in $\mathrm{D}_{2} \mathrm{O}$ at $25^{\circ} \mathrm{C}$ and $\mathrm{I}=1.0(\mathrm{KCl})$. Figure S5-Semilogarithmic plots between $\mathrm{pD}=2.03$ and $\mathrm{pD}=3.66$ of the fraction of unexchanged substrate against time for the $C(3)-\mathrm{H} / \mathrm{D}$ exchange reaction of $\mathbf{7}$ in solutions of $\mathrm{DCl}$ in $\mathrm{D}_{2} \mathrm{O}$ at $25^{\circ} \mathrm{C}$ and $\mathrm{I}=1.0$ $(\mathrm{KCl})$. Table $\mathrm{S} 1-$ First order rate constants for exchange of the $\mathrm{C} 3-\mathrm{H}$ of triazolium salt 6 for deuterium, in solutions of $\mathrm{DCl}$ in $\mathrm{D}_{2} \mathrm{O}$ at $25^{\circ} \mathrm{C}$ and $\mathrm{I}=1.0(\mathrm{KCl})$. Data for $\mathrm{pD}$ values of $3.07-3.66$ were obtained as part of this work. Table S2-First order rate constants for exchange of the $\mathrm{C}(3)-\mathrm{H}$ of triazolium salt 7 for deuterium in solutions of $\mathrm{DCl}$ in $\mathrm{D}_{2} \mathrm{O}$ at $25^{\circ} \mathrm{C}$ and $\mathrm{I}=1.0(\mathrm{KCl})$. Figure S6-Linear plot of $\log$ $k_{\text {ex }}$ against $\mathrm{p} D$ for the H/D exchange of triazolium salt $6(\bullet)$ and $7(\bullet)$ at $\mathrm{p} D$ values $\leq 1.1,25^{\circ} \mathrm{C}$ and $\mathrm{I}=1.0(\mathrm{KCl})$. Figure S7-Plot of $\log k_{\mathrm{ex}}$ versus $\mathrm{p} D$ for the $C(3)-\mathrm{H} / \mathrm{D}$ exchange of $\mathbf{6}(\bullet)$ and $7(\bullet)$ using eqn. 3 (main text), with $K_{\mathrm{a}}{ }^{\mathrm{N}}$ fixed to different values. Figure S8-Representative ${ }^{1} \mathrm{H}$ NMR at 400 $\mathrm{MHz}$ of 8 ( $10 \mathrm{mM}, \mathrm{pD} 1.08)$ during exchange of $\mathrm{C}(3)-\mathrm{H}(\mathrm{s}, 9.76 \mathrm{ppm})$ for deuterium in $\mathrm{DCl}$ solution in $\mathrm{D}_{2} \mathrm{O}$ at $25^{\circ} \mathrm{C}$ and $\mathrm{I}=1.0(\mathrm{KCl})$. [internal standard, tetramethylammonium deuteriosulphate (s, $3.17 \mathrm{ppm})$ ]. Figure S9-Representative ${ }^{1} \mathrm{H}$ NMR at $400 \mathrm{MHz}$ of 9 (10 mM, pD 1.08) during exchange of $\mathrm{C}(3)-\mathrm{H}(\mathrm{s}, 9.82 \mathrm{ppm})$ for deuterium in $\mathrm{DCl}$ solution in $\mathrm{D}_{2} \mathrm{O}$ at $25{ }^{\circ} \mathrm{C}$ and $\mathrm{I}=1.0(\mathrm{KCl})$. [internal standard, tetramethylammonium deuteriosulphate (s, $3.17 \mathrm{ppm}$ )]. Figure S10-Semilogarithmic plot of the fraction of unexchanged substrate against time for the deuterium exchange reaction of 8 in solutions of $\mathrm{DCl}$ in $\mathrm{D}_{2} \mathrm{O}$ at $25^{\circ} \mathrm{C}$ and $\mathrm{I}=1.0(\mathrm{KCl})$. Figure $\mathrm{S} 11$-Semilogarithmic plot of the fraction of unexchanged substrate against time for the deuterium exchange reaction of 8 in solutions of varying formate buffer concentration in $\mathrm{D}_{2} \mathrm{O}$ at $25^{\circ} \mathrm{C}$ and $\mathrm{I}=1.0(\mathrm{KCl})$. Figure S12-Semilogarithmic plots of the fraction of unexchanged substrate against time for the deuterium exchange reaction of 9 in solutions of $\mathrm{DCl}$ in $\mathrm{D}_{2} \mathrm{O}$ at $25{ }^{\circ} \mathrm{C}$ and $\mathrm{I}=1.0(\mathrm{KCl})$. Figure S13-Semilogarithmic plots of the fraction of unexchanged substrate against time for the deuterium exchange reaction of 9 in solutions of varying formate buffer concentration in $\mathrm{D}_{2} \mathrm{O}$ at $25{ }^{\circ} \mathrm{C}$ and $\mathrm{I}=1.0(\mathrm{KCl})$. Table S3-First order rate constants for exchange of the $\mathrm{C}(3)-\mathrm{H}$ of triazolium salt 8 for deuterium in solutions of $\mathrm{DCl}$ in $\mathrm{D}_{2} \mathrm{O}$ at $25^{\circ} \mathrm{C}$ and $\mathrm{I}=1.0(\mathrm{KCl})$. Table S4-First order rate constants for exchange of the C(3)- $\mathrm{H}$ of triazolium salt 9 for deuterium in solutions of $\mathrm{DCl}$ in $\mathrm{D}_{2} \mathrm{O}$ at $25^{\circ} \mathrm{C}$ and $\mathrm{I}=1.0(\mathrm{KCl})$. Table S5-First order rate constants for exchange of the $\mathrm{C}(3)$ - $\mathrm{H}$ of triazolium salt $\mathbf{8}$ for deuterium, with varying formate buffer concentration, in solutions of $\mathrm{DCl}$ in $\mathrm{D}_{2} \mathrm{O}$ at $25^{\circ} \mathrm{C}$ and $\mathrm{I}=1.0(\mathrm{KCl})$. Table S6-First order rate constants for exchange of the $\mathrm{C}(3)-\mathrm{H}$ of triazolium salt 9 for deuterium, with varying formate buffer concentration, in solutions of $\mathrm{DCl}$ in $\mathrm{D}_{2} \mathrm{O}$ at $25^{\circ} \mathrm{C}$ and $\mathrm{I}=1.0(\mathrm{KCl})$. Figure $\mathrm{S} 14-$ Structures of pyrid-2-yl triazolium salts for which DFT calculations were undertaken of energies as a function of dihedral angle of the monocation, dication from N1 protonation (N1 dication) and dication from protonation of the pyrid-2-yl nitrogen (pyridyl dication). Figure S15-Conformational profiles of monocationic N-5-methoxypyrid-2-yl 7 (-) and the two dicationic forms afforded from $N$-protonation of the triazolyl $\mathrm{N}(1)(-)$ or the pyridyl nitrogen (-) obtained by DFT calculations using B3LYP (6-311G++(d,p) basis set, PCM methanol). Figure S16-The effect of dihedral angle between $N$-aryl and triazolium ring on the calculated energy of the dication of 6 resulting from pyrid-2-yl nitrogen protonation obtained using B3LYP/6-311g++ $(d, p)$ or M062X/6-311g++ $(d, p)$ with PCM (water). Points are calculated energies with the solid curve an interpolation between the data points.

Author Contributions: Conceptualization, A.C.O. and P.Q.; methodology, A.C.O. and P.Q.; kinetic experiments, P.Q.; synthesis, P.Q.; computational modelling, M.S.S., J.Z., and P.Q.; writing-original draft preparation, A.C.O. and M.S.S.; writing-review and editing, D.R.W.H.; supervision, A.C.O. and D.R.W.H. All authors have read and agreed to the published version of the manuscript.

Funding: We thank the EPSRC (PQ, EP/M506321/1; MSS, EP/S022791/1; JZ, EP/S020713/1) for funding.

Data Availability Statement: All kinetic data are contained within the article or Supplementary Materials. 
Acknowledgments: We are grateful to the Durham Chemistry NMR service for their ongoing help and support. We also thank Dmitry S. Yufit of the Durham Chemistry Crystallography Service for X-ray crystallography for 6 and 7.

Conflicts of Interest: The authors declare no conflict of interest.

\section{References and Notes}

1. Breslow, R. On the mechanism of thiamine action. IV. 1 Evidence from studies on model systems. J. Am. Chem. Soc. 1958, 80, 3719-3726. [CrossRef]

2. Hachisu, Y.; Bode, J.W.; Suzuki, K. Catalytic intramolecular crossed aldehyde-Ketone benzoin reactions: A novel synthesis of functionalized preanthraquinones. J. Am. Chem. Soc. 2003, 125, 8432-8433. [CrossRef]

3. Li, G.-Q.; Dai, L.-X.; You, S.-L. Thiazolium-derived N-heterocyclic carbene-catalyzed cross-coupling of aldehydes with unactivated imines. Chem. Commun. 2007, 852-854. [CrossRef]

4. Delany, E.G.; Connon, S.J. Enantioselective N-heterocyclic carbene-catalysed intermolecular crossed benzoin condensations: Improved catalyst design and the role of in situ racemisation. Org. Biomol. Chem. 2020, 19, 248-258. [CrossRef]

5. Rose, C.A.; Gundala, S.; Fagan, C.L.; Franz, J.F.; Connon, S.J.; Zeitler, K. NHC-catalysed, chemoselective crossed-acyloin reactions. Chem. Sci. 2012, 3, 735-740. [CrossRef]

6. O'Toole, S.E.; Rose, C.A.; Gundala, S.; Zeitler, K.; Connon, S.J. Highly chemoselective direct crossed aliphatic-aromatic acyloin condensations with triazolium-derived carbene catalysts. J. Org. Chem. 2011, 76, 347-357. [CrossRef]

7. Ramanjaneyulu, B.T.; Mahesh, S.; Vijaya Anand, R. N-heterocyclic carbene catalyzed highly chemoselective intermolecular crossed acyloin condensation of aromatic aldehydes with trifluoroacetaldehyde ethyl hemiacetal. Org. Lett. 2015, 17, 6-9. [CrossRef] [PubMed]

8. Sunoj, R.B.; Pareek, M.; Reddi, Y. Tale of the Breslow Intermediate, a Central Player in N-Heterocyclic Carbene Organocatalysis: Then and Now. Chem. Sci. 2021, 12, 7973-7992.

9. Berkessel, A.; Harnying, W.; Sudkaow, P.; Biswas, A. N-Heterocyclic Carbene/Carboxylic Acid Co-Catalysis Enables Oxidative Esterification of Demanding Aldehydes/Enals, at Low Catalyst Loading. Angew. Chem. Int. Ed. 2021, 60, 19631-19636.

10. Grasa, G.A.; Kissling, R.M.; Nolan, S.P. N-heterocyclic carbenes as versatile nucleophilic catalysts for transesterification/acylation reactions. Org. Lett. 2002, 4, 3583-3586. [CrossRef]

11. Nyce, G.W.; Lamboy, J.A.; Connor, E.F.; Waymouth, R.M.; Hedrick, J.L. Expanding the catalytic activity of nucleophilic Nheterocyclic carbenes for transesterification reactions. Org. Lett. 2002, 4, 3587-3590. [CrossRef]

12. Zeitler, K. Stereoselective synthesis of (E)-alpha,beta-unsaturated esters via carbene-catalyzed redox esterification. Org. Lett. 2006, 8, 637-640. [CrossRef] [PubMed]

13. Grasa, G.A.; Güveli, T.; Singh, R.; Nolan, S.P. Efficient transesterification/acylation reactions mediated by N-heterocyclic carbene catalysts. J. Org. Chem. 2003, 68, 2812-2819. [CrossRef]

14. Lai, C.L.; Lee, H.M.; Hu, C.H. Theoretical study on the mechanism of N-heterocyclic carbene catalyzed transesterification reactions. Tetrahedron Lett. 2005, 46, 6265-6270. [CrossRef]

15. Singh, R.; Nolan, S.P. Synthesis of phosphorus esters by transesterification mediated by N-heterocyclic carbenes (NHCs). Chem. Commun. 2005, 5456-5458. [CrossRef] [PubMed]

16. Singh, R.; Kissling, R.M.; Letellier, M.-A.; Nolan, S.P. Transesterification/acylation of secondary alcohols mediated by Nheterocyclic carbene catalysts. J. Org. Chem. 2004, 69, 209-212. [CrossRef] [PubMed]

17. Chai, Y.; Li, Y.; Hu, H.; Zeng, C.; Wang, S.; Xu, H.; Gao, Y. N-Heterocyclic Carbene Functionalized Covalent Organic Framework for Transesterification of Glycerol with Dialkyl Carbonates. Catalysts. 2021, 11, 423. [CrossRef]

18. Zeng, T.; Song, G.; Li, C.-J. Separation, recovery and reuse of N-heterocyclic carbene catalysts in transesterification reactions. Chem. Commun. 2009, 41, 6249-6251. [CrossRef]

19. Du, G.-F.; Guo, H.; Wang, Y.; Li, W.-J.; Shi, W.-J.; Dai, B. N-heterocyclic carbene catalyzed synthesis of dimethyl carbonate via transesterification of ethylene carbonate with methanol. J. Saudi Chem. Soc. 2015, 19, 112-115. [CrossRef]

20. Sohn, S.S.; Rosen, E.L.; Bode, J.W. N-heterocyclic carbene-catalyzed generation of homoenolates: Gamma-butyrolactones by direct annulations of enals and aldehydes. J. Am. Chem. Soc. 2004, 126, 14370-14371. [CrossRef]

21. He, M.; Bode, J.W. Catalytic Synthesis of gamma-Lactams via direct annulations of enals and N-sulfonylimines. Org. Lett. 2005, 7, 3131-3134. [CrossRef]

22. Rommel, M.; Fukuzumi, T.; Bode, J.W. Cyclic ketimines as superior electrophiles for NHC-catalyzed homoenolate additions with broad scope and low catalyst loadings. J. Am. Chem. Soc. 2008, 130, 17266-17267. [CrossRef]

23. Sun, L.-H.; Shen, L.-T.; Ye, S. Highly diastereo- and enantioselective NHC-catalyzed [3+2] annulation of enals and isatins. Chem. Commun. 2011, 47, 10136-10138. [CrossRef]

24. Guo, C.; Fleige, M.; Janssen-Müller, D.; Daniliuc, C.G.; Glorius, F. Switchable selectivity in an NHC-catalysed dearomatizing annulation reaction. Nature Chem. 2015, 7, 842. [CrossRef]

25. Yetra, S.R.; Mondal, S.; Mukherjee, S.; Gonnade, R.G.; Biju, A.T. Enantioselective Synthesis of Spirocyclohexadienones by NHC-Catalyzed Formal [3+3] Annulation Reaction of Enals. Angew. Chem. Int. Ed. 2016, 55, 268-272. [CrossRef]

26. Xie, Y.; Li, L.; Sun, S.; Wu, Z.; Lang, M.; Jiang, D.; Wang, J. Enantioselective NHC-Catalyzed [3+3] Annulation of $\alpha$-Bromoenals with 2-Aminobenzimidazoles. Org. Lett. 2020, 22, 391-394. [CrossRef] 
27. Liu, L.; Guo, D.; Wang, J. NHC-Catalyzed Asymmetric $\alpha$-Regioselective [4+2] Annulation to Construct $\alpha$-Alkylidene- $\delta$-lactones. Org. Lett. 2020, 22, 7025-7029. [CrossRef]

28. Lyngvi, E.; Bode, J.W.; Schoenebeck, F. A computational study of the origin of stereoinduction in NHC-catalyzed annulation reactions of $\alpha, \beta$-unsaturated acyl azoliums. Chem. Sci. 2012, 3, 2346-2350. [CrossRef]

29. Nguyen, X.B.; Nakano, Y.; Duggan, N.M.; Scott, L.; Breugst, M.; Lupton, D.W. N-Heterocyclic Carbene Catalyzed (5+1) Annulations Exploiting a Vinyl Dianion Synthon Strategy. Angew. Chem. Int. Ed. 2019, 58, 11483-11490. [CrossRef]

30. Draskovits, M.; Kalaus, H.; Stanetty, C.; Mihovilovic, M.D. Intercepted dehomologation of aldoses by N-heterocyclic carbene catalysis-a novel transformation in carbohydrate chemistry. Chem. Commun. 2019, 55, 12144-12147. [CrossRef]

31. Zhao, L.-L.; Li, X.-S.; Cao, L.-L.; Zhang, R.; Shi, X.-Q.; Qi, J. Access to dihydropyridinones and spirooxindoles: Application of $\mathrm{N}$-heterocyclic carbene-catalyzed [3+3] annulation of enals and oxindole-derived enals with 2-aminoacrylates. Chem. Commun. 2017, 53, 5985-5988. [CrossRef]

32. Schedler, M.; Wurz, N.E.; Daniliuc, C.G.; Glorius, F. N-Heterocyclic carbene catalyzed umpolung of styrenes: Mechanistic elucidation and selective tail-to-tail dimerization. Org. Lett. 2014, 16, 3134-3137. [CrossRef]

33. Flanigan, D.M.; Romanov-Michailidis, F.; White, N.A.; Rovis, T. Organocatalytic Reactions Enabled by N-Heterocyclic Carbenes. Chem. Rev. 2015, 115, 9307-9387. [CrossRef]

34. Enders, D.; Breuer, K.; Raabe, G.; Runsink, J.; Teles, J.H.; Melder, J.P.; Ebel, K.; Brode, S. Preparation, Structure, and Reactivity of 1,3,4-Triphenyl-4,5-Dihydro-1h-1,2,4-Triazol-5-Ylidene, a New Stable Carbene. Angew. Chem. Int. Ed. 1995, 34, 1021-1023. [CrossRef]

35. Enders, D.; Breuer, K.; Raabe, G.; Simonet, J.; Ghanimi, A.; Stegmann, H.B.; Teles, J.H. A stable carbene as $\pi$-acceptor electrochemical reduction to the radical anion. Tetrahedron Lett. 1997, 38, 2833-2836. [CrossRef]

36. Enders, D.; Breuer, K.; Teles, J.; Ebel, K. 1, 3, 4-Triphenyl-4, 5-dihydro-1H-1, 2, 4-triazol-5-ylidene-applications of a stable carbene in synthesis and catalysis. J. Prakt. Chem. 1997, 339, 397-399. [CrossRef]

37. Nair, V.; Vellalath, S.; Babu, B.P. Recent advances in carbon-carbon bond-forming reactions involving homoenolates generated by NHC catalysis. Chem. Soc. Rev. 2008, 37, 2691-2698. [CrossRef]

38. Zhao, C.; Blaszczyk, S.A.; Wang, J. Asymmetric reactions of N-heterocyclic carbene (NHC)-based chiral acyl azoliums and azolium enolates. Green Synth. Catal. 2021, 2, 198-215. [CrossRef]

39. Song, R.; Jin, Z.; Chi, Y.R. NHC-catalyzed covalent activation of heteroatoms for enantioselective reactions. Chem. Sci. 2021, 12, 5037-5043. [CrossRef]

40. Dai, L.; Ye, S. Recent advances in N-heterocyclic carbene-catalyzed radical reactions. Chin. Chem. Lett. 2020, 32, 660-667. [CrossRef]

41. Enders, D.; Niemeier, O.; Henseler, A. Organocatalysis by N-heterocyclic carbenes. Chem. Rev. 2007, 107, 5606-5655. [CrossRef]

42. Grossmann, A.; Enders, D. N-heterocyclic carbene catalyzed domino reactions. Angew. Chem. Int. Ed. 2012, 51, 314-325. [CrossRef]

43. Chen, X.Y.; Liu, Q.; Chauhan, P.; Enders, D. N-Heterocyclic Carbene Catalysis via Azolium Dienolates: An Efficient Strategy for Remote Enantioselective Functionalizations. Angew. Chem. Int. Ed. 2018, 57, 3862-3873. [CrossRef]

44. Knight, R.L.; Leeper, F.J. Comparison of chiral thiazolium and triazolium salts as asymmetric catalysts for the benzoin condensation. J. Chem. Soc.-Perkin Trans. 1 1998, 1891-1893. [CrossRef]

45. Campbell, C.D.; Collett, C.J.; Thomson, J.E.; Slawin, A.M.; Smith, A.D. Organic base effects in NHC promoted O-to C-carboxyl transfer; chemoselectivity profiles, mechanistic studies and domino catalysis. Org. Biomol. Chem. 2011, 9, 4205-4218. [CrossRef] [PubMed]

46. Campbell, C.D.; Concellón, C.; Smith, A.D. Catalytic enantioselective Steglich rearrangements using chiral N-heterocyclic carbenes. Tetrahedron Asymmetry 2011, 22, 797-811. [CrossRef]

47. Baragwanath, L.; Rose, C.A.; Zeitler, K.; Connon, S.J. Highly enantioselective benzoin condensation reactions involving a bifunctional protic pentafluorophenyl-substituted triazolium precatalyst. J. Org. Chem. 2009, 74, 9214-9217. [CrossRef]

48. DiRocco, D.A.; Oberg, K.M.; Dalton, D.M.; Rovis, T. Catalytic asymmetric intermolecular stetter reaction of heterocyclic aldehydes with nitroalkenes: Backbone fluorination improves selectivity. J. Am. Chem. Soc. 2009, 131, 10872-10874. [CrossRef]

49. Enders, D.; Kallfass, U. An efficient nucleophilic carbene catalyst for the asymmetric benzoin condensation. Angew. Chem. Int. Ed. 2002, 41, 1743-1745. [CrossRef]

50. Collett, C.J.; Massey, R.S.; Maguire, O.R.; Batsanov, A.S.; O’Donoghue, A.C.; Smith, A.D. Mechanistic insights into the triazolylidene-catalysed Stetter and benzoin reactions: Role of the N-aryl substituent. Chem. Sci. 2013, 4, 1514-1522. [CrossRef]

51. Collett, C.J.; Massey, R.S.; Taylor, J.E.; Maguire, O.R.; O'Donoghue, A.C.; Smith, A.D. Rate and equilibrium constants for the addition of N-heterocyclic carbenes into benzaldehydes: A remarkable 2-substituent effect. Angew. Chem. Int. Ed. 2015, 54, 6887-6892. [CrossRef]

52. Massey, R.S.; Murray, J.; Collett, C.J.; Zhu, J.; Smith, A.D.; O'Donoghue, A.C. Kinetic and structure-activity studies of the triazolium ion-catalysed benzoin condensation. Org. Biomol. Chem. 2021, 19, 387-393. [CrossRef]

53. Collett, C.J.; Young, C.M.; Massey, R.S.; O’Donoghue, A.C.; Smith, A.D. Kinetic and Structure-Activity Studies of the Triazolium Ion-catalyzed Intramolecular Stetter Reaction. Eur. J. Org. Chem. 2021, 26, 3670-3675. [CrossRef]

54. Wu, S.; Liu, C.; Luo, G.; Jin, Z.; Zheng, P.; Chi, Y.R. NHC-Catalyzed Chemoselective Reactions of Enals and Aminobenzaldehydes for Access to Chiral Dihydroquinolines. Angew. Chem. Int. Ed. 2019, 58, 18410-18413. [CrossRef] [PubMed] 
55. Menon, R.S.; Biju, A.T.; Nair, V. Recent advances in N-heterocyclic carbene (NHC)-catalysed benzoin reactions. Beilstein J. Org. Chem. 2016, 12, 444-461. [CrossRef]

56. Mahatthananchai, J.; Bode, J.W. The effect of the N-mesityl group in NHC-catalyzed reactions. Chem. Sci. 2012, 3, 192-197. [CrossRef]

57. Delany, E.G.; Connon, S.J. Highly chemoselective intermolecular cross-benzoin reactions using an ad hoc designed novel N-heterocyclic carbene catalyst. Org. Biomol. Chem. 2018, 16, 780-786. [CrossRef] [PubMed]

58. Raed, A.A.; Dhayalan, V.; Barkai, S.; Milo, A. N-Heterocyclic Carbene Triazolium Salts Containing Brominated Aromatic Motifs: Features and Synthetic Protocol. CHIMIA 2020, 74, 878-882. [CrossRef] [PubMed]

59. Mayr, H.; Ofial, A.R. Philicities, fugalities, and equilibrium constants. Acc. Chem. Res. 2016, 49, 952-965. [CrossRef] [PubMed]

60. Higgins, E.M.; Sherwood, J.A.; Lindsay, A.G.; Armstrong, J.; Massey, R.S.; Alder, R.W.; O'Donoghue, A.C. pK $\mathrm{a}_{\mathrm{a}}$ of the conjugate acids of N-heterocyclic carbenes in water. Chem. Commun. 2011, 47, 1559-1561. [CrossRef]

61. Massey, R.S.; Collett, C.J.; Lindsay, A.G.; Smith, A.D.; O’Donoghue, A.C. Proton transfer reactions of triazol-3-ylidenes: Kinetic acidities and carbon acid $\mathrm{p} K_{\mathrm{a}}$ values for twenty triazolium salts in aqueous solution. J. Am. Chem. Soc. 2012, 134, 20421-20432 [CrossRef] [PubMed]

62. O'Donoghue, A.C.; Massey, R.S. Contemporary carbene chemistry. In Contemporary Carbene Chemistry; Moss, R.A., Doyle, M.P., Eds.; John Wiley \& Sons: Hoboken, NJ, USA, 2013.

63. Tucker, D.E.; Quinn, P.; Massey, R.S.; Collett, C.J.; Jasiewicz, D.J.; Bramley, C.R.; Smith, A.D.; O’Donoghue, A.C. Proton transfer reactions of N-aryl triazolium salts: Unusual ortho-substituent effects. J. Phys. Org. Chem. 2015, 28, 108-115. [CrossRef]

64. Massey, R.S.; Quinn, P.; Zhou, S.; Murphy, J.A.; O’Donoghue, A.C. Proton transfer reactions of a bridged bis-propyl bisimidazolium salt. J. Phys. Org. Chem. 2016, 29, 735-740. [CrossRef]

65. Amyes, T.L.; Diver, S.T.; Richard, J.P.; Rivas, F.M.; Toth, K. Formation and stability of N-heterocyclic carbenes in water: The carbon acid $\mathrm{pK} K_{\mathrm{a}}$ of imidazolium cations in aqueous solution. J. Am. Chem. Soc. 2004, 126, 4366-4374. [CrossRef]

66. Magill, A.M.; Cavell, K.J.; Yates, B.F. Basicity of nucleophilic carbenes in aqueous and nonaqueous solvents theoretical predictions. J. Am. Chem. Soc. 2004, 126, 8717-8724. [CrossRef]

67. Konstandaras, N.; Dunn, M.H.; Guerry, M.S.; Barnett, C.D.; Cole, M.L.; Harper, J.B. The impact of cation structure upon the acidity of triazolium salts in dimethyl sulfoxide. Org. Biomol. Chem. 2020, 18, 66-75. [CrossRef] [PubMed]

68. Wang, N.; Xu, J.; Lee, J.K. The importance of N-heterocyclic carbene basicity in organocatalysis. Org. Biomol. Chem. 2018, 16, 8230-8244. [CrossRef]

69. Paul, M.; Detmar, E.; Schlangen, M.; Breugst, M.; Neudörfl, J.M.; Schwarz, H.; Berkessel, A.; Schäfer, M. Intermediates of N-Heterocyclic Carbene (NHC) Dimerization Probed in the Gas Phase by Ion Mobility Mass Spectrometry: C - H $\cdots: C$ Hydrogen Bonding Versus Covalent Dimer Formation. Chem. Eur. J. 2019, 25, 2511-2518. [CrossRef]

70. Dunn, M.H.; Konstandaras, N.; Cole, M.L.; Harper, J.B. Targeted and Systematic Approach to the Study of $\mathrm{p} K_{\mathrm{a}}$ Values of Imidazolium Salts in Dimethyl Sulfoxide. J. Org. Chem. 2017, 82, 7324-7331. [CrossRef] [PubMed]

71. Li, Z.; Li, X.; Cheng, J.-P. An Acidity Scale of Triazolium-Based NHC Precursors in DMSO. J. Org. Chem. 2017, 82, 9675-9681. [CrossRef]

72. Nelson, D.J.; Nolan, S.P. Quantifying and understanding the electronic properties of N-heterocyclic carbenes. Chem. Soc. Rev. 2013, 42, 6723-6753. [CrossRef]

73. Chu, Y.; Deng, H.; Cheng, J.-P. An acidity scale of 1, 3-dialkylimidazolium salts in dimethyl sulfoxide solution. J. Org. Chem. 2007, 72, 7790-7793. [CrossRef]

74. Kim, Y.-J.; Streitwieser, A. Basicity of a Stable Carbene, 1, 3-Di-tert-butylimidazol-2-ylidene, in THF. J. Am. Chem. Soc. 2002, 124, 5757-5761. [CrossRef] [PubMed]

75. Alder, R.W.; Allen, P.R.; Williams, S.J. Stable carbenes as strong bases. J. Chem. Soc. Chem. Commun. 1995, 12, 1267-1268. [CrossRef]

76. Dhayalan, V.; Gadekar, S.C.; Alassad, Z.; Milo, A. Unravelling mechanistic features of organocatalysis with in situ modifications at the secondary sphere. Nat. Chem. 2019, 11, 543-551. [CrossRef]

77. Zak, I.L.; Gadekar, S.C.; Milo, A. Designing the Secondary Coordination Sphere in Small-Molecule Catalysis. Synlett 2021, 32, 329-336. [CrossRef]

78. Hartwig, J.F. Synthesis, Structure, and Reactivity of a Palladium Hydrazonato Complex: A New Type of Reductive Elimination Reaction to Form C-N Bonds and Catalytic Arylation of Benzophenone Hydrazone. Angew. Chem. Int. Ed. 1998, 37, $2090-2093$. [CrossRef]

79. Wagaw, S.; Yang, B.H.; Buchwald, S.L. A palladium-catalyzed strategy for the preparation of indoles: A novel entry into the Fischer indole synthesis. J. Am. Chem. Soc. 1998, 120, 6621-6622. [CrossRef]

80. Wagaw, S.; Yang, B.H.; Buchwald, S.L. A palladium-catalyzed method for the preparation of indoles via the Fischer indole synthesis. J. Am. Chem. Soc. 1999, 121, 10251-10263. [CrossRef]

81. Kerr, M.S.; Read de Alaniz, J.; Rovis, T. An efficient synthesis of achiral and chiral 1,2,4-triazolium salts: Bench stable precursors for N-heterocyclic carbenes. J. Org. Chem. 2005, 70, 5725-5728. [CrossRef] [PubMed]

82. As $\mathrm{p} D=-\log \mathrm{a}_{\mathrm{D}^{+}}$therefore $10^{-\mathrm{p} D}=\mathrm{a}_{\mathrm{D}^{+}}=\gamma^{\mathrm{D}+}\left[\mathrm{D}^{+}\right]$. 
83. In our previous publication in relation to 6 , we used a rate constant $k^{\prime}\left(\mathrm{s}^{-1}\right)$ rather than $k_{\mathrm{H}}\left(\mathrm{s}^{-1}\right)$ to describe the H/D-exchange reaction of substrate in the region of close to -1 slope. Owing to the consideration of an additional $\mathrm{p} D$-independent region in the present manuscript, and the need for a third rate constant to describe this region, we have changed $k^{\prime}\left(\mathrm{s}^{-1}\right)$ to $k_{\mathrm{H}}\left(\mathrm{s}^{-1}\right)$ for the -1 region. The latter more clearly denotes a region involving formal acid catalysis.

84. Lee, C.; Yang, W.; Parr, R.G. Development of the Colle-Salvetti correlation-energy formula into a functional of the electron density. Phys. Rev. B 1988, 37, 785-789. [CrossRef] [PubMed]

85. Krishnan, R.; Binkley, J.S.; Seeger, R.; Pople, J.A. Self-consistent molecular orbital methods. XX. A basis set for correlated wave functions. J. Phys. Chem. 1980, 72, 650-654. [CrossRef]

86. Clark, T.; Chandrasekhar, J.; Spitznagel, G.W.; Schleyer, P.V.R. Efficient diffuse function-augmented basis sets for anion calculations. III. The 3-21+ G basis set for first-row elements, Li-F. J. Comput. Chem. 1983, 4, 294-301. [CrossRef]

87. Tomasi, J.; Mennucci, B.; Cammi, R. Quantum mechanical continuum solvation models. Chem. Rev. 2005, 105, 2999-3094. [CrossRef]

88. Zhao, Y.; Truhlar, D.G. The M06 suite of density functionals for main group thermochemistry, thermochemical kinetics, noncovalent interactions, excited states, and transition elements: Two new functionals and systematic testing of four M06-class functionals and 12 other functionals. Theor. Chem. Acc. 2008, 120, 215-241. 